\title{
THE EFFECTS OF A COMPREHENSIVE TEACHING PROGRAM ON DRIBBLING AND PASSING DECISION-MAKING AND EXECUTION SKILLS OF YOUNG FOOTBALLERS
}

\author{
Alba Práxedes Pizarro1, Alberto Moreno Domínguez ${ }^{1}$, Javier Sevil Serrano², \\ Luis García-González ${ }^{2}$, and Fernando del Villar Álvarez ${ }^{3}$ \\ ${ }^{1}$ Faculty of Sport Sciences, University of Extremadura, Cáceres, Spain \\ ${ }^{2}$ Faculty of Health and Sport Sciences, University of Zaragoza, Huesca, Spain \\ ${ }^{3}$ Faculty of Health Sciences, Physical Education Area, \\ University Rey Juan Carlos, Madrid, Spain
}

Original scientific paper

UDC: 796.332-053.6:159.94

\begin{abstract}
:
The importance of decision-making on what to do and skill execution within sport expertise has been emphasized in many research studies. Thus, the aim of this study was to assess the effect of a 22-session comprehensive teaching program on tactical behavior in agreement with different actions (passing and dribbling) in young footballers. This program was based on the Teaching Games for Understanding (TGfU) model (Bunker \& Thorpe, 1982). A quasi-experimental design intervention was developed with nine footballers (U-12) over a 15-week period, which was divided into two phases: pre-intervention (comprised of six sessions and measured during three matches) and intervention (comprised of 22 sessions and measured during 12 matches). Two measures were carried out during the latter phase: an intermediate measure during the first 11 sessions and a final measure during the remaining 11 sessions. A total of 2432 actions were observed (1 793 passes and 639 dribbling actions). Results showed a significant improvement in decision-making and skill execution capabilities after the 22, sessions but not after the first 11 sessions. In addition, differences were found between the two game actions, given that a significant improvement was encountered in both variables of the pass action, but only in the execution variable of the dribbling action. These findings highlight the need to know which type of action is going to be trained (more tactical or technical) in order to adapt the training session methodology. It also seems that, for the teaching program to be effective, it should be applied over a longer timeline of at least 22 sessions.
\end{abstract}

Key words: cognitive processes, young footballers, on-the-ball skills, TGfU, modified games

\section{Introduction}

From the cognitive psychology approach, the sport expertise level depends on cognitive processes (e.g. decision-making) that evolve from the interpretation of a stimulus to the selection of a response (García-González, Moreno, Gil, Moreno, \& Del Villar, 2014). These cognitive elements become even more important in open skill sports, like football (McPherson, 2008). Several authors have observed how the capacity to make decisions has an important role in achieving expert performance (Araujo, Keith, \& Hristovski, 2006), taking into account the development of tactical knowledge and cognitive skills.

The Teaching Games for Understanding (TGfU) model, developed by Bunker and Thorpe (1982), is now one of the models that favors most this decision-making capacity in athletes (Griffin,
Brooker, \& Patton, 2005). TGfU is a game- and learner-centered model for learning games, where players are encouraged to develop their problemsolving skills, critical thinking and autonomy of thought (Richard \& Wallian 2005). In this regard, the TGfU model focuses the teaching on contents (both tactics and skills) in small-game learning contexts (Bunker \& Thorpe, 1982). The objective of this model, based on the pedagogical principles of modified games (sampling, representation, exaggeration and tactical complexity) and questioning, is to understand the game through tactical knowledge (Gray \& Sproule, 2011).

This has led to the traditional model being questioned as it offers athletes a limited decisionmaking capacity (for a review, see Stolz \& Pill, 2014). In this sense, Bunker and Thorpe (1982) created the TGfU model arguing that traditional 
approaches focused on teaching technical skills with an analytical approach, making it impossible for learners to generalize practice to real game conditions (Light, Harvey, \& Mouchet, 2014). Furthermore, in the traditional model, sport sessions emphasize a skills-first approach where skills are learned before rules and game play are introduced, and its objective is to develop "technical proficiency" (Oslin \& Mitchell, 2006:627).

Small-sided and modified games became a central feature in the TGfU model (Thorpe, Bunker, \& Almond, 1986). Coaches may, then, propose different modified versions of the real game, manipulating the structural elements (i.e. dimensions of the game space, number of players, play time, etc.) in order to simplify or adapt the original version of the sport, but always considering the learning level and the evolving characteristics of their trainees (Harvey, Cushion, \& Massa-Gonzalez, 2010a). It is important to highlight that one of the objectives of small-sided games is to amplify information sources to guide athletes towards their objectives (Araújo \& Davids, 2009; Passos, Araújo, Keith, $\&$ Shuttleworth, 2008). This is possible using the pedagogical exaggeration principle (manipulation of structural elements such as attack game principles, opposition level, rules of the game, and number or dimensions of the goals). On the other hand, the aim of the different tasks presented to the trainees is to provide variability in practice and favor an unpredictable learning environment, coming close to a real game situation. In this regard, Ward et al. (2008) indicate the need to use representative tasks that include the essential aspects that characterize the game situations. Furthermore, real game situations must be used to evaluate the effectiveness of the intervention programs, assessing athletes in the real game context (Travassos, et al., 2013). A substantial body of research focuses on the role of modified games both in professional and adult football (Passos, et al., 2008; Psotta \& Martin, 2011), and in the early stages of football (Serra, GarcíaLópez, \& Sánchez-Mora, 2011), indicating that it is a methodological resource that causes changes in tactical behavior and that it may be used to improve components such as decision-making in game.

On the other hand, when the TGfU model is applied, it is necessary to highlight the use of questioning as a cognitive tool that permits focusing attention on specific technical-tactical aspects by means of questions that the coach asks the athletes (Vickers, 2007). On this aspect, Webb and Pearson (2008) indicate the usefulness of applying questioning (through interrogative feedback) to favor cognitive development and thus create a critical and reflexive attitude in athletes (Gréhaigne, Richard, \& Griffin, 2005), consequently improving their tactical behavior, such as decision-making (GarcíaGonzález, et al., 2014), and also technical compo- nents of their motor execution in open-skill sports (Gil \& del Villar, 2014).

Along this line, different intervention studies which focus on the development of comprehensive methodologies, have analysed their effect on decision-making and execution variables, both in a Physical Education (PE) context (Hastie, Sinelnikov, \& Guarino, 2009; Turner \& Martinek, 1999) and in a sport training context (Del Villar, GarcíaGonzález, Iglesias, Moreno, \& Cervelló, 2007; García-González, et al., 2014). Favorable results were observed after the intervention program was carried out in players who followed a comprehensive approach, improving players' decision-making and execution variables.

However, there is no agreement in the scientific community about how long the comprehensive teaching programs to train young athletes should last, although the idea prevails that, to obtain significant differences, extensive programs (of at least 15 sessions) must be developed (Turner \& Martinek, 1999). Along this line, authors such as Gray and Sproule (2011), and Harvey, Cushion, Wegis, and Massa-González, (2010b) did not encounter differences in their eight and 10-session studies, respectively. MacMahon and McPherson (2009) point out that the influence of procedural knowledge on the different cognitive processes that determine decision-making, as a result of adaptations in the memory, occur in the long term.

Regarding the effectiveness of comprehensive teaching programs, authors such as Psotta and Martin (2011), and Turner and Martinek (1999) have observed differences in the improvement of tactical behavior between different actions (passing and dribbling) within the same sport. More specifically, these authors observed that actions such as passing improved after the comprehensive teaching program, whilst actions such as dribbling improved, as well, but using a more technical approach. Likewise, Gutiérrez and García-López (2012) and Vera, Pino, Romero, and Moreno (2007), in their descriptive studies in both the educational and sporting context, showed that there were significant differences between different game actions. This arises a question of whether the same teaching model should or should not be used to teach all the game actions in the athletes' formative process. In this regard, technically more complicated game actions may require the application of a more traditional approach, whilst game actions with a prevalence of decision-making components require a comprehensive methodology.

Very few studies have been found to date in scientific literature that explore the differences that might exist between game actions in the same sport after the application of comprehensive and traditional approaches (in football, Psotta, \& Martin, 2011; in hockey, Turner, \& Martinek, 1999). There- 
fore, the main aim of this study was to determine if there were differences in athletes' tactical behavior between different game actions after a comprehensive teaching program application.

Specifically, the first objective was to analyse the effect of the application of the comprehensive teaching program, comprised of 22 training sessions, on the decision-making and execution variables of footballers in their formative years. The second objective was to analyse the effect of the comprehensive teaching program on the decision-making and execution variables of both game actions - passing and dribbling in football. Two hypotheses are proposed: (1) the intervention program will facilitate improvement of decisionmaking and execution in young footballers after 22 sessions; and (2) the intervention program will cause a greater effect in the pass action than in the dribbling action as manifested in the decisionmaking and execution variables.

\section{Methods}

\section{Participants}

Nine male football players, aged between 10 and 11 years $(10.55 \pm 0.52)$ and with experience in federated football of between three and six years $(4.88 \pm 0.78)$ took part in the study. All players belonged to the U-12 category, to the same team and to the same training group. Players were characterized for having an intermediate sport expertise level, playing in the regional league. All of them trained for two one-hour sessions each week. Participants and their parents were informed before the study and signed the informed consent as required by the Helsinki Declaration and the local ethics committee.

\section{Design}

An intra-group quasi-experimental design was carried out. Two research phases were considered in order to analyse the intervention program. The first, pre-intervention phase was comprised of six sessions during which a technical model was used (emphasizing a skills-first approach where skills are learned before introducing rules and game play), and the second, intervention phase was comprised of 22 comprehensive teaching sessions based on the TGFU model.

\section{Variables}

Dependent variables of this study were decisionmaking and skill execution. Decision-making is defined as the adaptation of the selected response to the specific conditions of a game situation, based on an observation instrument (Nielsen \& McPherson, 2001). It was measured by the percentage of successful decisions over the total number of decisions made. Execution is defined as the performance, outcome, or the final result of the skill execution (Nielsen, \& McPherson, 2001). It was measured by the percentage of successful executions over the total number of executions made. The number of appropriate and inappropriate passing and dribbling actions were recorded, from the decision and execution viewpoint, using the Game Performance Evaluation Tool (GPET) (García-López, González-Víllora, Gutiérrez, \& Serra, 2013). A total of 2432 actions were observed (1 793 passes and 639 dribbling actions). Decision-making and execution were analysed for each action.

\section{Comprehensive teaching program}

The comprehensive teaching program was identified as the independent variable. The program based on the TGfU model was applied for 22 training sessions (one hour per session) over a 12 -week period. The objectives of each session of the intervention program are presented in Table 1, always seeking to integrate technical and tactical contents.

In order to guarantee correct application of the teaching program, the coach, who had one year of experience, was instructed by an expert. The expert was a professor in Sport and Exercise Sciences and he had 12 years of experience in teaching football at young stages. As in the study by Harvey et al. (2010b), the training program to instruct the coach was developed over three sessions, each one lasting for an hour and a half. In the first session, the basic principles of the TGfU model were addressed; in the second emphasis was on the application of modified games, and the last session addressed the use of questioning in the formation of young football players. The coach prepared the sessions prior to each intervention, including the questions that were going to be asked. To ensure that the model was correctly applied (Hastie, \& Cassey, 2014), the training sessions were supervised by a researcher with 15 years of experience in supervising teaching methodologies. The researcher also attended the training sessions. The characteristics of the teaching program were as follows:

Task design (manipulating the task-related determining factors). The tasks were designed in accordance with the complexity of the game, progressively increasing the level of uncertainty that football players had to cope with. Thus, in each training session, and after a two-minute warm-up at low intensity, four 15-minute tasks, with a high cognitive component (task with constant uncertainty in the game environment where the player has to select a response), were performed. In each task some determining factors were modified (e.g. attack game principles, number of players, opposition level: equal or unequal number of players per team, space, goal and time). An example of a task including objective: progression and attack on the opposite goal with the least opposition level; nume- 
Table 1. Scheme of work used in the study

\begin{tabular}{lcc}
\hline Session & \multicolumn{2}{c}{ Session objectives } \\
\cline { 2 - 3 } number & Attack & Defense \\
\hline 1 & Mobility to create lines of pass & Prevent lines of passes and anticipation \\
2 & Dealing with crosses & Occupy spaces \\
3 & Penetration (attack the goal) & Covering \\
4 & Space (width and depth in attack) & Closing down \\
6 & Mobility to keep possession & Occupy spaces \\
7 & Protect the ball & \\
8 & Penetration (creation of numerical advantage) & \\
9 & Space (width and depth in attack) & Balance (cut lines of passes) \\
10 & Mobility to switch positions & Pressing \\
11 & Creation and occupation of free spaces & Marking \\
12 & Mobility to create lines of pass & Covering \\
13 & Penetration (attack the goal) & Prevent lines of passes and anticipation \\
14 & Creation and occupation of free spaces & Balance (cut lines of passes) \\
15 & Mobility to keep possession & Covering \\
16 & Protect the ball & Occupy spaces \\
17 & Dealing with crosses & \\
18 & & Occupy spaces \\
$\mathbf{2 0}$ & & Balance (cut lines of passes) \\
\hline 21 & Penetration (creation of numerical advantage) & Marking \\
\hline
\end{tabular}

rical superiority in attack; explanation of the task: perform a 2vs.1 with the goalkeeper from midfield; activity variants: modifying the task-related determining factors, which the coach proposed depending on the success of the task performance, in order to make it progressively more complicated (number of players: 2vs.2; opposition level: $2 \mathrm{vs} .2$ with a semi-active defense; size of the field: the size of the field reduced by two meters each side; and time: limit the duration of a move to 15 seconds).

Questioning. The application of the questioning with the aim to cognitively involve the player, who requires a greater selection capacity, which would, to a certain extent, benefit his decisionmaking quality. Based on Vickers' decision training model (2007), which establishes three steps to be followed, the protocol was designed: 1) Questions were focused on a tactical principle to be dealt with during each task (e.g. Why did you decide to pass to player 1 or to player 2 ? What made you decide which was the best moment to pass?); 2) After the question had been asked, there was a pause to let the athlete prepare a reflexive answer; 3) After the task completion, the players discussed the application of the tactical concept dealt with for a maximum of two minutes. Therefore, the questioning was carried out twice during each task - once after a few minutes had elapsed to guide them in the task and then at the end to consolidate these concepts. Additionally, and during the task, the coach put questions to those players who did not solve the task.

\section{Instruments}

The GPET observation instrument (GarcíaLópez, et al., 2013) was used to assess the decisionmaking and skill execution of the observed football players. This instrument is a football adaptation of the original Game Performance Assessment Instrument (GPAI) (Oslin, Mitchell, \& Griffin, 1998), which was created to assess performance in the game from the sport-specific tactical viewpoint. This permitted evaluating the players' tactical problem-solving skills by means of their selection and application of an appropriate technique.

This instrument (GPET), which has already been used for other studies in young football players (e.g. Gutiérrez, Fisette, García-López, \& Contreras, 2014) allows the evaluation of both measures in real game situations, as recommended by Travassos et al. (2013). All the pass and dribbling actions of each and every player on the team were recorded (F-7). The decision-making component of this instrument was used to evaluate decision-making by assigning 1 to appropriate decisions and 0 to inappropriate decisions (Table 2).

The execution component of the same instrument was used to evaluate skill execution by assigning 1 to successful executions and 0 to unsuccessful executions (Table 3). 
Table 2. GPET coding procedures for decision-making (soccer) (García-López, et al., 2013)

\begin{tabular}{|c|c|c|}
\hline \multirow{3}{*}{ 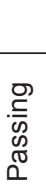 } & & DECISION-MAKING \\
\hline & 1 & - Passing to a teammate who is unmarked. \\
\hline & 0 & $\begin{array}{l}\text { - Passing to a teammate who is marked closely or there is a defensive player in a position to cut off the pass. } \\
\text { - Passing to an area of the pitch where no teammate is positioned. }\end{array}$ \\
\hline \multirow{2}{*}{ 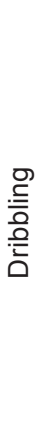 } & 1 & $\begin{array}{l}\text { - Taking the ball upfield, whilst not closely marked, to a free space. } \\
\text { - An appropriate change of direction away from a defender (right or left) to an open area of the pitch. } \\
\text { - The player advances by positioning his body between the opponent and the ball in order to protect the ball. } \\
\text { - The player does not move and protects the ball with his body when the defender pressurizes him, and does not } \\
\text { have the option of attacking. }\end{array}$ \\
\hline & 0 & $\begin{array}{l}\text { - Charging. } \\
\text { - Dribbling when there is an unmarked teammate in a better position. } \\
\text { - A player advancing the ball when an opponent is close and has a very good chance of winning the ball. } \\
\text { - A player advancing the ball and not protecting the ball with the body when an opponent is close. } \\
\text { - Dribbling away from the goal, dribbling with the ball without going forward or attacking the defense. } \\
\text { - The player does not move and does not protect the ball with his body when the defender pressurizes him, and } \\
\text { does not have the option of attacking. }\end{array}$ \\
\hline
\end{tabular}

Table 3. GPET coding procedures for execution (soccer) (García-López, et al., 2013)

\begin{tabular}{|c|c|c|}
\hline \multicolumn{3}{|r|}{ EXECUTION } \\
\hline \multirow[b]{2}{*}{$\begin{array}{l}\text { D } \\
\frac{.}{\infty} \\
0 \\
0 \\
0\end{array}$} & 1 & $\begin{array}{l}\text { - Successful pass to a teammate: to his body if he is stationary, lead pass if he is running. } \\
\text { - Appropriate length and speed. }\end{array}$ \\
\hline & 0 & $\begin{array}{l}\text { - Pass intercepted } \\
\text { - Pass is too hard. } \\
\text { - Pass out of play. } \\
\text { - Pass is too far behind or in front of a teammate. }\end{array}$ \\
\hline \multirow[b]{2}{*}{$\begin{array}{l}\frac{.0}{2} \\
\frac{0}{0} \\
\frac{0}{2}\end{array}$} & 1 & - Successfully attacking with the ball. \\
\hline & 0 & $\begin{array}{l}\text { - Loss of the control over the ball. } \\
\text { - Loss of the ball due to a legal challenge. } \\
\text { - Commits a foul (offensive foul). }\end{array}$ \\
\hline
\end{tabular}

The following audiovisual and technological means were used to develop this research: a SONY VAIO laptop computer, a Sony HDRXR155 video camera, a recording angle conversion lens ( $\mathrm{x} 0.75)$ : VCL-HGA07B, and a Hama Gamma Series tripod. The camera was always placed in the middle of the playing field, at a height of 4 meters, thus guaranteeing an optimal view of all the game actions.

\section{Observation reliability}

An observer, with knowledge of football and three years of experience in observational methodology, was trained to analyse the decision-making and skill execution of the pass and dribbling actions. More than $10 \%$ of the total sample was used to train the observer. Cohen's kappa coefficient was used for the intra-observer reliability analysis, obtaining values of above .90 in four training sessions. Thus, .81 level was exceeded, which is the minimum value required to consider adequate concordance (Fleiss, Levi, \& Cho Paik, 2003), obtaining the necessary reliability for subsequent dependent variable coding. For the time reliability analysis of the measure, the same coding was developed at two different moments, with a time difference of 10 days, and Cohen's kappa values of over .85 were obtained.

\section{Procedure}

Two research phases were considered in this study:

Pre-intervention phase. To establish the players' initial decision-making and skill execution level prior to the intervention, different values of the respective game actions were recorded and registered. During this phase, lasting six sessions, the coach designed tasks in agreement with the technical teaching model. This differed from real game situations and in the majority of occasions there was no opposition and no questioning was applied. Values of both variables were obtained by the players in three matches corresponding to the first three league games.

Intervention phase. Twenty-two training sessions were developed in this phase, conducted twice a week, each one lasting one hour. In parallel with this, and to know the effect of applying the intervention program, 12 matches were recorded, 
one per week, to observe the participants' decisionmaking and skill execution. Two measures were carried out in this phase to assess the game performance of the athletes. An intermediate measure was carried out based on the observation of the first six matches played by the team, during the first 11 intervention sessions (half the process), and another, final measure was carried out by collecting data from the other six matches, played during the other 11 sessions. This was done to verify the timeline the intervention program required to be effective. The average score in each variable was taken to record the data throughout the six matches analysed at each measure moment, thus counteracting the possible effect of the opponents' variability.

\section{Statistical analysis}

The statistical program SPSS 19.0 was used to analyse and process the data. Firstly, the data normality was examined. The asymmetry measures, kurtosis, Shapiro-Wilk (for samples of 30 or less) with Lilliefors correction, verified that the sample distribution did not follow a normal distribution $(\mathrm{p}<.005)$, establishing the need to use non-parametric statistics. Then, the descriptive statistics were calculated for the decision-making and execution variables. Then, the Friedman test showed whether there were significant differences between the different research phases in each technical-tactical skill. Finally, and in order to verify the existing differences between the pre-intervention measure and each of the two measures of the intervention phase, an inferential analysis was performed using the Wilcoxon test for measures related to Bonferroni correction (significance level of $.05 / 3=.016$ ).

\section{Results}

\section{Analysis of total game performance}

In the within-group analysis, performed using the Friedman test, the contrast statistics showed significant differences between the three measures developed in the study (the pre-intervention, intermediate, and final measure) in the decision-making (Chi-square $=14.000, \mathrm{gl}=2, \mathrm{p}=.001$ ) and execution skills (Chi-square $=13.556, \mathrm{gl}=2, \mathrm{p}=.001$ ). Pairwise comparisons (Table 4) showed significant differences, in both the decision-making and execution skills, between the pre-intervention and final measures $(p=.008)$, the mean of the second measure being greater. However, these differences were not found between the pre-intervention and intermediate measures.

\section{Analysis of the decision-making and execution skill of the pass action}

In the pass action, the contrast statistics showed significant differences between the three measures developed in the study (the pre-intervention, intermediate, and final measure) in the decision-making (Chi-square $=14.000, g l=2, p=.001$ ) and execution skills (Chi-square $=13.556, \mathrm{gl}=2, \mathrm{p}=.001)$. Pairwise comparisons (Table 5) showed significant differences in both the decision-making and execution skill between the pre-intervention and final measures $(\mathrm{p}=.008)$, the mean of the second measure being greater. However, no differences were found between the pre-intervention and intermediate measures.

Table 4. Descriptive statistics and pairwise comparison of total game performance for intragroup analysis

\begin{tabular}{lcccccccc}
\hline & \multicolumn{3}{c}{ Test-time } & \multicolumn{3}{c}{ Test-time } & \multirow{2}{*}{ Wilcoxon Z } & $\mathrm{p}^{\mathrm{a}}$ \\
\cline { 2 - 7 } & $\mathrm{T}^{\prime}$ & $\mathrm{M}$ & $\mathrm{SD}$ & $\mathrm{T}^{\prime}$ & $\mathrm{M}$ & $\mathrm{SD}$ & & \\
\hline \multirow{2}{*}{ Decision-making skills } & Pre & .719 & .172 & Intermediate & .801 & .043 & -1.244 & .214 \\
& Pre & .719 & .172 & Final & .896 & .028 & -2.666 & .008 \\
\hline \multirow{2}{*}{ Execution skills } & Pre & .543 & .165 & Intermediate & .587 & .082 & -.533 & .594 \\
& Pre & .543 & .165 & Final & .758 & .090 & -2.666 & .008 \\
\hline
\end{tabular}

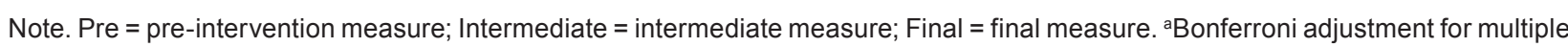
comparisons.

Table 5. Descriptive statistics and pairwise comparison of decision-making and execution of the pass action

\begin{tabular}{|c|c|c|c|c|c|c|c|c|}
\hline & \multicolumn{3}{|c|}{ Test-time } & \multicolumn{3}{|c|}{ Test-time } & \multirow{2}{*}{ Wilcoxon Z } & \multirow{2}{*}{$\mathrm{p}^{\mathrm{a}}$} \\
\hline & $\mathrm{T}^{\prime}$ & M & SD & $\mathrm{T}^{\prime}$ & M & SD & & \\
\hline \multirow{2}{*}{ Decision-making } & Pre & .677 & .178 & Intermediate & .761 & .070 & -1.481 & .139 \\
\hline & Pre & .677 & .178 & Final & .866 & .069 & -2.666 & .008 \\
\hline \multirow{2}{*}{ Execution } & Pre & .544 & .182 & Intermediate & .594 & .063 & -.770 & .441 \\
\hline & Pre & .544 & .182 & Final & .739 & .064 & -2.666 & .008 \\
\hline
\end{tabular}

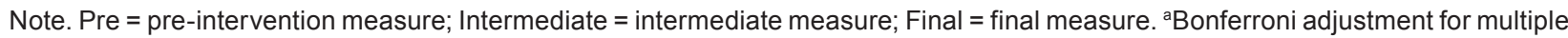
comparisons. 


\section{Analysis of the decision-making and execution skills of the dribbling action}

In the dribbling action, the contrast statistics showed significant differences between the three measures developed in the study (pre-intervention, intermediate, and final measure) in the decision-making (Chi-square $=3.935, \mathrm{gl}=2, \mathrm{p}=.140$ ) and execution skills (Chi-square $=3.935, \mathrm{gl}=2, \mathrm{p}=.140$ ). Pairwise comparisons (Table 6) showed significant differences in the execution skill between the preintervention and final measures $(\mathrm{p}=.028)$, the mean of the second measure being greater. However, no differences were found in the decision-making and between the pre-intervention and intermediate measures. and McPherson (2009) point out, this may be due to the fact that the influence of knowledge on different cognitive processes that determine decisionmaking and adaptations in the memory is felt in the long term, thus these comprehensive methodologies require a longer learning period in formative age of trainees.

Hence, we can point out that the intervention program applied in its entirety (22 sessions) has allowed optimizing cognitive variables in our study. Players reached a higher cognitive expertise level and developed their selection skills of the most appropriate tactical responses in the attack action (Gutiérrez, González-Víllora, García-López, \& Mitchell, 2011; Nielsen \& McPherson, 2001) as

Table 6. Descriptive statistics and pairwise comparison of decision-making and execution of the dribbling action

\begin{tabular}{lcccccccc}
\hline & \multicolumn{3}{c}{ Test-time } & \multicolumn{3}{c}{ Test-time } & \multirow{2}{*}{ Wilcoxon Z } & $\mathrm{p}^{\mathrm{a}}$ \\
\cline { 2 - 7 } & $\mathrm{T}^{\prime}$ & $\mathrm{M}$ & $\mathrm{SD}$ & $\mathrm{T}^{\prime}$ & $\mathrm{M}$ & $\mathrm{SD}$ & & \\
\hline \multirow{2}{*}{ Decision-making } & Pre & .820 & .119 & Intermediate & .836 & .060 & -.140 & .889 \\
& Pre & .820 & .119 & Final & .919 & .060 & -1.859 & .063 \\
\hline \multirow{2}{*}{ Execution } & Pre & .588 & .234 & Intermediate & .560 & .165 & -.280 & .779 \\
& Pre & .588 & .234 & Final & .761 & .165 & -2.197 & .028 \\
\hline
\end{tabular}

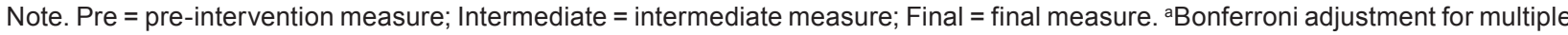
comparisons.

\section{Discussion and conclusions}

The aim of this research study was to analyse the effect of a comprehensive teaching program, comprised of 22 training sessions, on the decisionmaking and execution variables of footballers in their formative age. The first hypothesis was that the intervention program would need to be applied for at least 22 sessions to give rise to improvement in the decision-making and execution variables in young footballers. The results obtained show that there were no significant differences between the pre-intervention and intermediate measure in any of the variables studied. However, the significant differences were found between the pre-intervention and final measures, with higher values in both the decision-making and execution variables after the intervention program. The first hypothesis was thus confirmed. These results show that the comprehensive teaching program, applied in its entirety, that is, in the extended length ( 22 sessions), led to a significant improvement in the decision-making and execution capacity of the observed young athletes.

These findings seem to show that, for there to be a significant improvement in the learners' decision-making and execution capacity after applying a comprehensive teaching program, the length of the program must be extensive, as determined by previous studies that indicated the need for programs to include more than 12 sessions (Harvey, et al., 2010b; Turner \& Martinek, 1999). As MacMahon well as better performance during the game (Del Villar, et al., 2007; Harvey, 2003). The application of questioning, as a formative instrument, has probably had a decisive influence on the results obtained, and its usefulness as a tool to improve decision-making and execution skills can be confirmed (García-González, et al., 2014; Gil, et al., 2014). Therefore, we can state that the extensive comprehensive teaching program, consisting of 22 sessions in our case, aiming at improving the tactical action in young football players, seems to be effective in producing a significant improvement in decision-making and in the technical execution of the skill.

The second objective was to analyse the effect of the comprehensive teaching program on the decision-making and execution variable of both game actions (pass and dribbling) in football. The second hypothesis predicted that the intervention program would cause a greater effect in the pass than in the dribbling action on the decision-making and execution variables. The results obtained in the pass action show the significant differences between the pre-intervention and final measure in both the decision-making and execution variable. With respect to the dribbling action, the significant differences were observed in execution between the pre-intervention and final measure, but not in the decisionmaking between any of the measures. The second hypothesis was thus confirmed. These results seem 
to show that during players' formative years in football (e.g. U12 category), the effects produced by a comprehensive teaching program may differ in agreement with the technical-tactical action studied. In this regard, the program was indeed effective in obtaining improvements in the pass action, but not in the decision-making of the dribbling action, even after 22 training sessions.

If we are to rely on the results of previous research studies, which also obtain differences in the improvement of athletes' tactical behavior between different actions of the same sport (Gutiérrez \& García-López, 2012; Vera, et al., 2007), it can be suggested that the differences obtained in our study were due to different characteristics of the pass and dribbling actions in football.

On this subject Vera et al. (2007) point out that, during initial learning stages, in the dribbling action in football, the aim of feedback must focus on both the technical and tactical corrections. In this case, the execution component is more complicated than the decision component. The pass action, however may be more closely associated with the decision component, given that its complexity lies more in deciding who to pass to and when than in the technical execution of the skill itself and, therefore, the teacher must give priority to the tactical aspects. Thus, a comprehensive methodology, based on cognitive aspects, may have a positive influence on a predominantly tactical skill such as passing and not on a predominantly technical skill such as dribbling in football.

In this regard, in their study with football players Psotta and Martin (2011) observed, after applying two intervention programs, that those players who were trained according to the tactical model, improved their decision-making and execution of the pass action, but not of the dribbling action. However, those who were trained according to the traditional model did improve in decision-making and execution of the dribbling action. Along this line, in their study on hockey Turner and Martinek (1999) obtained significant improvements in the pass action in favor of the group of students who were taught according to the TGfU model. On the other hand, they did not find any significant differences between the two groups in the dribbling action. Thus, in agreement with the findings obtained in our study, in which there has been no improvement of the decision-making component in the dribbling action, and those studies mentioned above, it seems that if we want to develop the dribbling skill more effectively in football during the first learning stages, a complementary practice based on the traditional model must be added to the practice based on the comprehensive model in order to guarantee the prevalence of the technical execution of this skill, prior to the decision-making improvement.

On the other hand, another possible explanation for these results may be that athletes in their formative years have more limitations in some technical-tactical contents than in others, as occurs with the dribbling-swerve action in football (GonzálezVíllora, García-López, Pastor, \& Contreras-Jordán, 2011). In this regard, in their study on the evolution of decision-making and technical skills in different federative categories of football, González-Víllora, García-López, \& Contreras-Jordán (2015) point out that the pass reaches a higher effectiveness index than the dribbling and swerve action, both in the context of keeping ball possession and progression towards the goal. Likewise, in their descriptive study on football in the PE context, Gutiérrez and García-López (2012) observed that in decision-making, the pass action obtained significantly higher values than the dribbling action. All of this seems to indicate that the pass skill obtains more favorable results in early sporting stages.

The study conducted represents a significant contribution to the development of comprehensive teaching programs, in agreement with the type of game actions. However, due to the use of a small sample and the intra-group design carried out, we must be cautious when considering the obtained results. Future research in this line is necessary to be able to establish more conclusive results and to continue to provide scientific knowledge about the validity of comprehensive models in sport teaching in agreement with the different game actions that are typical of each sport.

With reference to the two objectives studied, i.e. duration of the comprehensive teaching program and the types of game actions to be taught, we must highlight that the pass action in football has significantly improved both in terms of the decision-making and execution variables, but only after 22 sessions. These findings underline the need to understand that in predominantly tactical tasks, such as the pass action, extensive comprehensive teaching programs must be applied to allow players to assimilate the decision-based tactical principles and apply them effectively to execution in a real game context.

Insofar as the dribbling action in football is concerned, the comprehensive teaching program has not caused significant changes in the decisionmaking variable. Therefore, in teaching highly complicated technical skills, such as dribbling in football, it is decisive to start with a phase that follows technical model principles. This will guarantee that athletes will gain control over the technical execution of this skill prior to the decision-making improvement. 


\section{References}

Araújo, D., \& Davids, K. (2009). Ecological approaches to cognition and action in sport and exercise: Ask not only what you do, but where you do it. International Journal of Sport Psychology, 40(1), 5-37.

Araujo, D., Keith, W., \& Hristovski, R. (2006). The ecological dynamics of decision making in sport. Psychology of Sport and Exercise, 7(6), 653-676. doi:10.1016/j.psychsport.2006.07.002

Bunker, D., \& Thorpe, R. (1982). A model for the teaching of games in secondary schools. Bulletin of Physical Education, 18(1), 5-8.

Del Villar, F., García-González, L., Iglesias, D., Moreno, M.P., \& Cervelló, E.M. (2007). Expert-novice differences in cognitive and execution skills during tennis competition. Perceptual and Motor Skills, 104(2), 355-365. doi:10.2466/pms 104.2.355-365

Fleiss, J.L., Levi, B., \& Cho Paik, M. (2003). Statistical methods for rates and proportions (3 ${ }^{\text {rd }}$ ed.). New York: Wiley.

French, K., \& Thomas, J. (1987). The relation of knowledge development to children's basketball performance. Journal of Sport Psychology, 9(1), 15-32.

García-González, L., Moreno, A., Gil, A., Moreno, M.P., \& Del Villar, F. (2014). Effects of decision training on decision making and performance in young tennis players: An applied research. Journal of Applied Sport Psychology, 26(4), 426-440. doi:10.1080/10413200.2014.917441

García-López, L.M., González-Víllora, S., Gutiérrez, D., \& Serra, J. (2013). Development and validation of the Game Performance Evaluation Tool (GPET) in soccer. Revista Euroamericana de Ciencias Del Deporte, 2(1), 89-99.

Gil, A., \& del Villar, F. (2014). Aplicación de un programa de entrenamiento decisional, en tiempo real de juego, para la mejora de rendimiento táctico individual del deportista. [Implementation of a real-time decision-making training program for the improvement of individual tactical performance of athletes. In Spanish.] In L. GarcíaGonzález \& F. Del-Villar (Eds.), Entrenamiento táctico y decisional en el deporte (pp. 132-145). Madrid: Síntesis.

González-Víllora, S., García-López, L.M., \& Contreras-Jordán, O.R. (2015). Decision making and skill development in youth football players. Revista Internacional de Medicina y Ciencias de la Actividad Física y el Deporte, 15(59), 467-487. doi: 10.15366/rimcafd2015.59.005

González-Víllora, S., García-López, L. M., Pastor, J.C., \& Contreras-Jordán, O.R. (2011). Conocimiento táctico y toma de decisiones en jóvenes jugadores de fútbol (10 años). [Tactical knowledge and decision making in young football players (10 years old). In Spanish.] Revista de Psicología del Deporte, 20(1), 79-97.

Gray, S., \& Sproule, J. (2011). Developing pupils' performance in team invasion games. Physical Education and Sport Pedagogy, 16(1), 15-32. doi:10.1080/17408980903535792

Gréhaigne, J.F., Richard, J., \& Griffin, L. (2005). Teaching and learning team sports and games. New York: Routledge.

Griffin, L.L., Brooker, R., \& Patton, K. (2005). Working towards legitimacy: Two decades of Teaching Games for Understanding. Physical Education and Sport Pedagogy, 10(3), 213-223. doi:10.1080/17408980500340703

Gutiérrez, D., Fisette, J., García-López, L.M., \& Contreras, O. (2014). Assessment of secondary school students' game performance related to tactical contexts. Journal of Human Kinetics, 42, 223-234. doi:10.2478/hukin-2014-0076

Gutiérrez, D., \& García-López, L.M. (2012). Assessment of primary school students' decision-making related to tactical contexts. Journal of New Approaches in Educational Research, 1(1), 7-12. doi:10.7821/naer.1.1.7-12

Gutiérrez, D., González-Víllora, S., García-López, L.M., \& Mitchell, S. (2011). Diferences in decision-making development between expert and novice invasion game players. Perceptual and Motor Skills, 112(3), 871-888. doi: 10.2466/05.10.11.25.PMS.112.3.871-888

Harvey, S. (2003). Teaching Games for Understanding: A study of U19 college soccer players improvement in game performance using the game performance assessment instrument. Paper presented at The Sport and Physical Education for Understanding Conference (pp. 11-25). Melbourne: University of Melbourne.

Harvey, S., Cushion, C.J., \& Massa-Gonzalez, A.N. (2010a). Learning a new method: Teaching Games for Understanding in the coaches' eyes. Physical Education and Sport Pedagogy, 15(4), 361-382. doi:10.1080/17408980903535818

Harvey, S., Cushion, C.J., Wegis, H.M., \& Massa-Gonzalez, A.N. (2010b). Teaching Games for Understanding in American high-school soccer: A quantitative data analysis using the game performance assessment instrument. Physical Education and Sport Pedagogy, 15(1), 29-54. doi:10.1080/17408980902729354

Hastie, P.A., \& Casey, A. (2014). Fidelity in models-based practice research in sport pedagogy: A guide for future investigations. Journal of Teaching in Physical Education, 33, 422-431. doi.org/10.1123/jtpe.2013-0141

Hastie, P.A., Sinelnikov, O.A., \& Guarino, A.J. (2009). The development of skill and tactical competencies during a season of badminton. European Journal of Sport Science, 9(3), 133-140. doi: 10.1080/17461390802542564

Holt, J.E., Ward, P., \& Wallhead, T.L. (2006). The transfer of learning from play practices to game play in young adult soccer players. Physical Education and Sport Pedagogy, 11(2), 101-118. doi:10.1080/17408980600708270

Kirk, D., \& MacPhail, A. (2002). Teaching Games for Understanding and situated learning: Rethinking the BunkerThorpe model. Journal of Teaching in Physical Education, 21(2), 177-192.

Light, R.L., Harvey, S., \& Mouchet, A. (2014). Improving 'at-action' decision-making in team sports through a holistic coaching approach. Sport, Education and Society, 19(3), 258-275. doi: 10.1080/13573322.2012.665803

MacMahon, C., \& McPherson, S.L. (2009). Knowledge base as a mechanism for perceptual-cognitive tasks: Skill is in the details. International Journal of Sport Psychology, 40(4), 565-579. 
McPherson, S.L. (2008). Tactics: Using knowledge to enhace perfomance. In D. Farrow, J. Baker \& C. MacMahon (Eds.), Developing sport expertise: Researchers and coaches put theory into practice (pp. 155-167). London: Routledge.

Moreno, A., del Villar, F., García-González, L., Gil, A., \& Moreno M.P. (2011). Intervención en la toma de decisiones en jugadores de voleibol en etapas de formación. [Intervention in decision-making in volleyball players' formative stages. In Spanish.] Revista de Psicología del Deporte, 20(2), 785-800.

Nielsen, T.M., \& McPherson, S.L. (2001). Response selection and execution skills of professionals and novices during singles tennis competition. Perceptual and Motor Skills, 93, 541-555. doi: 10.2466/pms.2001.93.2.541

Oslin, J., \& Mitchell, S. (2006). Game-centred approaches to teaching physical education. In D. Kirk, D. Macdonald \& M. O’Sullivan (Eds.), The handbook of Physical Education (pp. 627-651). London: Sage Publications.

Oslin, J.L., Mitchell, S.A., \& Griffin, L. (1998). The Game Performance Assessment Instrument (GPAI): Development and preliminary validation. Journal of Teaching in Physical Education, 17, 231-243.

Passos, P., Araújo, D., Keith, D., \& Shuttleworth, R. (2008). Manipulating constraints to train decision making in rugby union. International Journal of Sports Science and Coaching, 3(1), 125-140. doi: 10.1260/174795408784089432

Piaget, J. (1964). PART 1. Cognitive development in children: Piaget. Development and learning. Journal of Research in Science Teaching, 2(3), 176-186. doi: 10.1002/tea.3660020306

Psotta, R., \& Martin, A. (2011). Changes in decision making skill and skill execution in soccer performance: The intervention study. Acta Universitatis Palackianae Olomucensis, Gymnica, 41(2), 7-15.

Richard, J., \& Wallian, N. (2005). Emphasizing student engagement in the construction of game performance. In L. Griffin \& J. Butler (Eds.), Teaching Games for Understanding: Theory, research and practice (pp. 19-32). Champaign, IL: Human Kinetics.

Serra, J., García-López, L.M., \& Sánchez-Mora, D. (2011). El juego modificado, recurso metodológico en el fútbol de iniciación. [The modified game, a methodological resource in football initiation. In Spanish.] Retos. Nuevas Tendencias en Educación Física, Deporte y Recreación, 20, 37-42.

Stolz, S., \& Pill, S. (2014). Teaching games and sport for understanding: Exploring and reconsidering its relevance in physical education. European Physical Education Review, 20(1), 36-71. doi:10.1177/1356336X13496001

Thorpe, R., Bunker, D., \& Almond, L. (1986) Rethinking games teaching. Loughborough: Loughborough University of Technology.

Travassos, B., Araújo, D., Davids, K., O’Hara, K., Leitão, J., \& Cortinhas, A. (2013). Expertise effects on decisionmaking in sport are constrained by requisite response behaviours - A meta-analysis. Psychology of Sport and Exercise, 14, 211-219. doi:10.1016/j.psychsport.2012.11.002

Turner, A., \& Martinek, T. J. (1999). An investigation into Teaching Games for Understanding: Effects on skill, knowledge and game play. Research Quarterly for Exercise and Sport, 70(3), 286-296.

Vickers, J.N. (2007). Perception, cognition, and decision training. The quiet eye in action. Champaign, IL: Human Kinetics.

Vera, G., Pino, J., Romero, C., \& Moreno, M.I. (2007). Propuesta de valoración técnico-táctica mediante una situación de juego colectivo básico en el fútbol de iniciación. [Proposal of evaluation of tactical-technical skill by means of a situation of basic collective games. In Spanish.] Retos. Nuevas Tendencias en Educación Física, Deporte y Recreación, 12, 29-35.

Ward, P., Farrow, D.W., Harris, K.R, Williams, A.M., Eccles, D.W., \& Ericsson, K.A. (2008). Training perceptualcognitive skills: Can sport psychology research inform military decision training? Military Psychology, 20(1), 71-102. doi: 10.1080/08995600701804814

Webb, P.I., \& Pearson, P.J. (2008). An integrated approach to Teaching Games for Understanding (TGfU). In 1st Asia Pacific Sport in Education Conference (pp. 1-11). Adelaide.

Submitted: March 7, 2016

Accepted: January 30, 2017

Correspondence to:

Alba Práxedes Pizarro

Faculty of Sport Sciences

University of Extremadura

Av. de la Universidad s/n, 10003, Cáceres, Spain

Phone: +34644208449

Fax: +34927257460

E-mail: apraxede@alumnos.unex.es 